\title{
Analysis of linear growth of Korean pine undergrowth (Pinus koraiensis sieb.et zucc) (Primorsky territory)
}

\author{
Natalia Rozlomiy ${ }^{1, *}$, Gennady Gukov ${ }^{1}$, and Stepan Kirpichnikov ${ }^{1}$ \\ ${ }^{1}$ Primorskaya State Academy of Agriculture, Blyukhera avenue 44, 692512, Ussuriysk, Russia
}

\begin{abstract}
Today, reforestation is becoming a priority task for Russia's forest policy, but many issues are still poorly understood. When developing forest plantation, many factors, both biotic and abiotic, are not taken into account, which leads to the death of the developed forest stands. The results of studies of provenance trial plantations of Siberian cedar (Pinus sibirica Du Tour) and Korean cedar (Pinus koraiensis Siebold et Zucc) in Krasnoyarsk Krai and Khabarovsk Krai are reflected in a number of works (Bratilova, 2004; Iroshnikov, 1983, 2001; Kuznetsova, 1998; Romanova et al., 1996; Koryakin et al., 1999, etc.). At the same time, the problems associated with the creation, growth and development of provenance trial plantation in the Primorsky Territory remain poorly understood. The aim of the work is to identify the nature of the interdependencies of linear growth of pine stands in various environmental conditions. The indicator studied in the paper is a series of deviations and linear growth from age states (i.e. growth indices), which characterize the degree of variability during tree growth. The object of measurements was a Korean pine on the territory of the forest area of the Primorskaya State Agricultural Academy.
\end{abstract}

\section{Research objects and methods}

The object of research was Korean pine undergrowth growing on the territory of the forest area of the Primorskaya State Agricultural Academy. The test plots were located on the territory of Rakovskoye forestry and Experimental forestry. For research, forest areas with a density of 0.4-0.8 were selected, and the method of statistical sample plots was used.

The work was carried out at the end of the growing season - in September. In total, 3 test plots were established. On each test plot, there were 6 experimental plots of $2 * 2 \mathrm{~m}$, where a selective enumeration of Korean pine undergrowth was carried out with measuring linear indicators.

On the established test plots, measurements of age increments by nods were carried out, as well as measurement of the height of the Korean pine undergrowth under different lighting conditions (forest stands of different density).

\footnotetext{
* Corresponding author: boss.shino@mail.ru
} 
Annual increments in height were measured for 417 pine undergrowth trees on 3 test plots.

Dendrochronological measurements of linear growth were carried out within the same test plots. Linear growth was measured in specimens with a height of at least $1 \mathrm{~m}$ and no higher than $2.5 \mathrm{~m}$. The choice of the latter object is caused by the need for massive, cheap, non-labor-intensive and non-damaging measurements for environmental monitoring. The comparability of the series of linear growth indices is determined, from our point of view, by the similarity of climatic and edaphic growing conditions, which largely determine the degree of growth variability.

\section{Research results}

To assess the success of natural renewal of pine according to the generally accepted method, 3 test plots were established (Table 1). The undergrowth was counted with a distribution by size categories (up to 0.5 - small; 0.6-1.5 m - medium; 1.6-3.5 m - large; 3.6 $\mathrm{m}$ and more - young). To study the nature of the development of pine undergrowth, measurements of annual growth in height were carried out on the three most different in composition and density (closeness) test plots. The height of the undergrowth was measured using a tape measure (table 2).

The test plot No. 1 was established in the 48th quarter, section 1. The type of forest on the test plot is cedar-spruce mossy-fern forest with fir and yellow birch forest CSLM. The sample is located in the upper part of the northeastern direction, the steepness of the slope is $35^{\circ}$. The soils are brown and gray mountain forest, thin, slightly humidified, fresh.

The forest stand on the test plot has the following composition: 3C2S2O1LM1YB1MP.

The test plot No. 2 was established in the 48th quarter, section 4. The type of forest on the test plot is ash-elm riparian forest AE. The sample is located in the middle part of the coastal protection strip. Soils are brown mountain forest, thin, slightly humus, fresh.

Composition of the forest stand: 3A1H1E2LM1MP1C1S.

The test plot No. 3 was established in the 38th quarter. The forest type on the test plot is white birch mixed forest WB. The sample is located in the middle part of the slope of the eastern direction, the steepness of the slope is $8^{\circ}$. The soils are brown and gray mountain forest, fresh.

Composition of the forest stand: 3C2MP1NF1C1A1LM1YB.

Table 1. Characteristics of test plots.

\begin{tabular}{|l|l|l|l|l|}
\hline No. & $\begin{array}{l}\text { Composition of the } \\
\text { forest stand }\end{array}$ & $\begin{array}{l}\text { Composition of } \\
\text { undergrowth }\end{array}$ & $\begin{array}{l}\text { Density / } \\
\text { closeness }\end{array}$ & $\begin{array}{l}\text { Number of } \\
\text { undergrowth }\end{array}$ \\
\hline $\mathbf{1}$ & 3C2S2O1LP1YB1MP & 6C2S2MP & $0.4 / 0.4$ & 131 \\
\hline $\mathbf{2}$ & 3A1H1E2LP1MP1C1S & 4C3S3E & $0.7 / 0.5$ & 174 \\
\hline $\mathbf{3}$ & 8O1LM1C+MP & 5MP4C1LM & $0.8 / 0.7$ & 112 \\
\hline
\end{tabular}

From the point of view of size and age, analysis of the growth of pine undergrowth in height over the years in absolute terms showed its dynamism.

The variation of the increment within the test plot may differ for all years or be the same in certain years. Perhaps this is due to the peculiarities of climatic conditions in different years.

The course of growth of pine in height has regularities - in all areas, the growth rate is higher, the higher the category of undergrowth.

If we compare the intensity of growth, then it can be noted that more favorable conditions for the growth of undergrowth in height are at TP-2. At the age of large undergrowth, the effect of density on an increase in growth is quite clearly traced: on TP-1, 
where the density is lowest, the increase in the growth is maximum; on TP-3, where the density is highest, the increase is minimum. In the middle category of undergrowth on TP3 , the increase in height increases with age $(2017-2.7 \mathrm{~cm}, 2018-7.3 \mathrm{~cm}, 2019-7.9 \mathrm{~cm})$ (Fig. 1).

Table 2. Characteristics of growth.

\begin{tabular}{|c|c|c|c|}
\hline \multicolumn{5}{|c|}{ Height gain, cm } \\
\hline TP-1 & $\mathbf{2 0 1 7}$ & $\mathbf{2 0 1 8}$ & $\mathbf{2 0 1 9}$ \\
\hline Large & 34.1 & 47.0 & 51.3 \\
\hline Medium & 22.3 & 26.1 & 32.5 \\
\hline Small & 8.8 & 11.8 & 16.6 \\
\hline TP-2 & & & \\
\hline Large & 68.7 & 63.5 & 72.3 \\
\hline Medium & 42.3 & 51.0 & 57.3 \\
\hline Small & 6.2 & 7.1 & 9.4 \\
\hline TP-3 & & & \\
\hline Large & 68.2 & 82.1 & 85.3 \\
\hline Medium & 11.2 & 26.4 & 19.1 \\
\hline Small & 6.0 & 8.2 & 8.3 \\
\hline
\end{tabular}

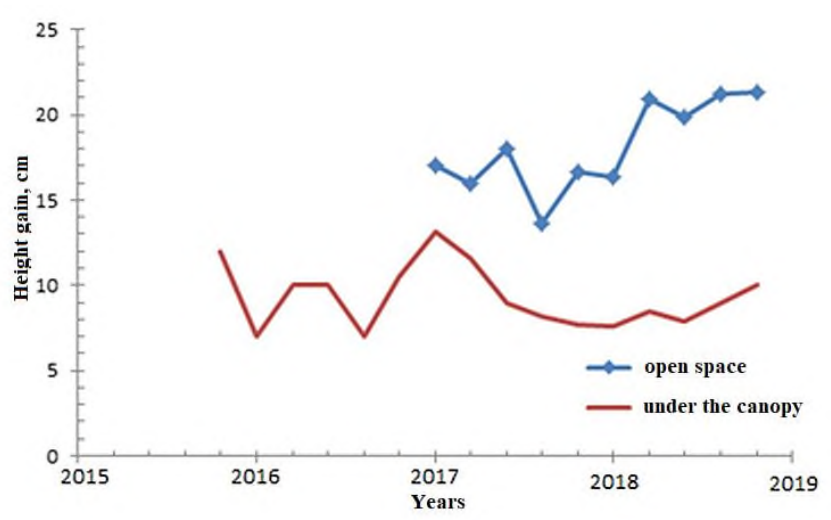

Fig. 1. Dependence of growth by years.

In large undergrowth, on the other hand, the increase in height decreases with age (2016 - $13.9 \mathrm{~cm}, 2017-8.4 \mathrm{~cm}, 2019-7.3 \mathrm{~cm}$ ). On TP-2, in both large and medium undergrowth, the increase in height decreases with age.

The study of the plots showed that the growth rate of medium undergrowth is lower than that of large undergrowth.

In order to identify the features of the growth in height to be able to analyze the undergrowth formed under the influence of environmental factors, graphs of the dependence of the increase by years and the increment taking into account age were built.

After analyzing the graph of the dependence of growth by years, we can say that on the TP with a density of 0.4 , the minimum growth of undergrowth was observed in 2017 2018 , and the maximum increase was recorded in 2019 . We can also say that the average growth varies within $7 \mathrm{~cm}$. With a forest stand density of 0.8 , the minimum growth of undergrowth was observed in 2016 and 2017, the maximum growth in 2018. The growth of pine undergrowth in height over the years in absolute terms showed its dynamism.

The change in the increment within the test plot may differ for all years or be similar in certain years. These changes in the growth of Scots pine can be explained by the fact that in 
different years climatic factors influenced the growth of pine undergrowth in different ways.

The graph of the dependence of growth on age shows that with a forest stand density of 0.4, the growth increases with age (direct relationship) (Fig. 2). The minimum growth of undergrowth was observed at the age of 4 years, the maximum - at 10 years. The higher the undergrowth category, the greater the growth rate. With a density of 0.8 , the minimum increase in growth was observed at the age of 8 years and increased sharply at the age of 9 years. With a high density of a forest stand, there is no such strict pattern as in low-density stands, since the growth is strongly affected by limiting factors (light, nutrients, flow and pressure of the environment, soil, fires, microenvironment, etc.).

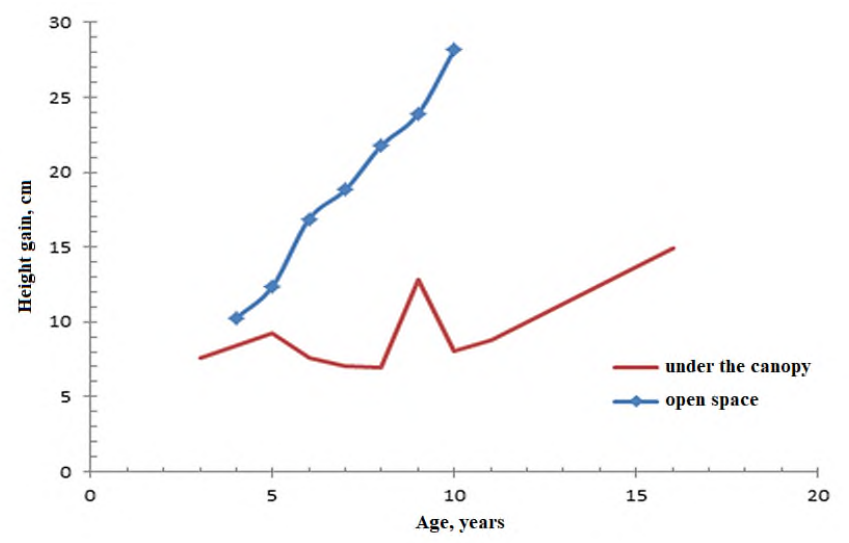

Fig. 2. Dependence of undergrowth growth on age.

When self-seeding, young trees have a poorly developed root system and a small leaf surface. As the roots and leaves grow, the assimilative capacity of the crowns increases, and the growth of wood increases. The weak growth of Korean pine undergrowth in highdensity forest stands is caused not only by the lack of light, but also by the fact that the trees of the parent stand, with their powerful and well-developed roots, take the maximum amount of nutrients and moisture from the soil. The vital activity of the roots is significantly affected by the water located on the illuvial horizon, which most often occurs in the spring after the snow melts. With its high location, the vital activity of the roots temporarily freezes, the duration of the growing season decreases and, as a result, growth decreases.

\section{Conclusion}

Having studied the distribution of groups of Korean pine undergrowth by age and by years in stands of different density, the following conclusions can be drawn:

- with low density, the minimum growth of undergrowth was observed in 2018, and the maximum growth was in 2019. Also, the larger the undergrowth, the greater the growth rate;

- with high density, the minimum growth of undergrowth was observed in 2016 and 2018 , the maximum growth was in 2017 , i.e. with high density of the forest stand, there is no definite pattern, as well as with a low one, since limiting factors (light, nutrients, flow and pressure of the environment, soil, fires, microenvironment, etc.) have a great influence on the growth of undergrowth; 
- the growth rate within the test plot may differ for all years, or be similar in certain years;

- at low density, the growth rate is much higher than at high one.

The maximum renewal -1.5 thousand $\mathrm{pcs} / \mathrm{ha}$ - is noted on TP-1 with the share of pine of 3 units; on TP-2, where pine is only in admixture, there is also a fairly large amount of undergrowth - $2000 \mathrm{pcs} / \mathrm{ha}$, which is explained by the characteristics of the soil. A clear decrease in the amount of undergrowth is observed with an increase in the density of the forest stand to 0.8 (TP-3). The identified features of the growth of pine undergrowth must be taken into account in the forest plantation development in the southern Far East.

\section{References}

1. E.M. Angalt, N.A. Zhamurina Analysis of the growth of pine undergrowth and young growth in pine and ash crops Izvestiya, 6 (44), 31-34 (2013)

2. A. Belov, N. Repsh, S. Berseneva Restoration of ecological and geological systems of disturbed lands of South Primorye, E3S Web of Conferences, 175, 06013 (2020) DOI: https://doi.org/10.1051/e3sconf/202017506013

3. G.V. Gukov Far Eastern forestry. Tutorial. Vladivostok. Publishing House of Far Eastern State University, 260, (1989)

4. N.M. Iteshina, L.N. Danilova, L.V. Petrov The growth and structure of pine stands in various forest conditions Scientific support for innovative development of agribusiness and agrarian education: Materials of the All-Russian scientific and practical conference, 1, 265-267 (2011)

5. A.E. Kukhta Linear growth of trees as an indicator of the state of the environment, Siberian ecological journal, 6, 767-771 (2003)

6. M. Sh. Machyk, A.A. Vais Assessment of the course of growth of morphological parameters of young pine stands taking into account their age structure in the conditions of the East Tuva-South Transbaikalia mountain forest site region Modern scientific research and innovations, 1 (57), 268-276 (2016)

7. G. Kozlov, et al. Bioindication for the Search of Microorganisms-Destructors. Advances in Intelligent Systems and Computing, pp 676-684 (2020) doi:10.1007/9783-030-57453-6_64

8. Handbook of the forest manager of the Far East. Far Eastern forest management company, 266, (1975)

9. M.S. Titova, N.G. Rozlomiy The reaction of the pigment system of Scots pine to technogenic pollution on the territory of historically significant objects of the city of Ussuriysk Bulletin of KrasGAU, 4, 170-173 (2014) 